\title{
Publisher Correction: Cold-induced epigenetic programming of the sperm enhances brown adipose tissue activity in the offspring
}

Wenfei Sun, Hua Dong, Anton S. Becker (D), Dianne H. Dapito, Salvatore Modica, Gerald Grandl, Lennart Opitz, Vissarion Efthymiou, Leon G. Straub, Gitalee Sarker, Miroslav Balaz, Lucia Balazova, Aliki Perdikari, Elke Kiehlmann, Sara Bacanovic, Caroline Zellweger, Daria Peleg-Raibstein, Pawel Pelczar, Wolf Reik, Irene A. Burger,

Ferdinand von Meyenn (iD and Christian Wolfrum

Correction to: Nature Medicine https://doi.org/10.1038/s41591-018-0102-y, published online 09 July 2018.

In the version of this article originally published, the bars in the mean temperature graph in Fig. 1a were incorrectly aligned. The leftmost bar should have been aligned with the Apr label on the projected month of conception axis. The error has been corrected in the print, PDF and HTML versions of this article.
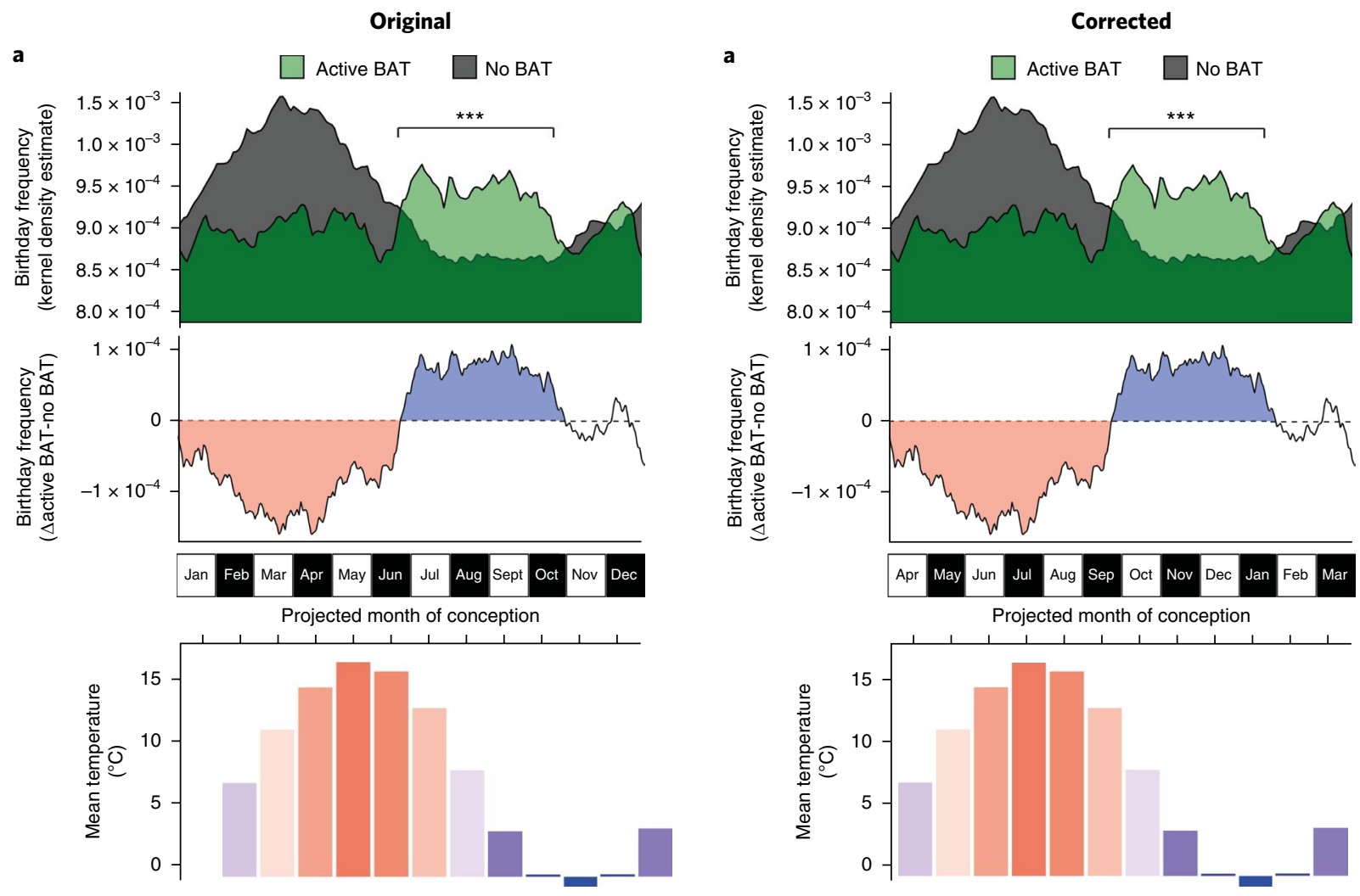

Fig. 1 | Original and Corrected.

Published online: 7 August 2018

https://doi.org/10.1038/s41591-018-0163-y 